\title{
SURFACE ACTIVITY OF HUMIC SUBSTANCES DEPENDING ON THEIR ORIGIN
}

\author{
Oskars Purmalis \\ Maris Klavins \\ University of Latvia, Latvia
}

\begin{abstract}
Humic substances are a general category of naturally occurring, biogenic, heterogeneous organic substances that can be characterised as being yellow to black in colour, of high molecular weight and refractory. Surface tension measurement defined humic substances as surface active substances. Unless micellar structural model of humic substances has been suggested, in the same time there are only a few studies about the factors that affect the surface activity of humic solutions. The objective of this study was to study changes in surface activity depending on the origin and properties of humic substances.
\end{abstract}

The surface tension-pH curves of humic substances featured a minimum for all solutions, declining steeply from higher and lower $\mathrm{pH}$ values. The decrease in surface tension with decreasing $\mathrm{pH}$ reflects the gradual neutralization of acidic sites, which created amphiphilic species that migrated to the surface. Surface tension of solutions of humic substances decreased with increasing concentration, as well as in presence of metal salts. Many industrially produced humic materials demonstrated no or insignificant impact on surface tension of their solutions, but humic substances isolated from natural environments (water, soil, peat, sediments) demonstrated significant impact of surface tension of their solutions. Thus there exist direct links between origin, structure of humic substances and their ability to influence surface tension of aquatic solutions.

\section{KEYWORDS}

Surface tension; Humic substances; Kinetics

\section{INTRODUCTION}

Humic substances (HS) are the most widely found naturally occurring organic substances. Humic substances are a general category of naturally occurring, biogenic, heterogeneous organic substances that can generally be characterised as being yellow to black in color, of high molecular weight and refractory. Humic substances can be divided into three fractions: a) humin is the fraction of humic substances that is not soluble in water at any $\mathrm{pH}$; b) humic acid (HA) is the fraction of humic substances that is not soluble in water under acidic conditions (below $\mathrm{pH} 2$ ), but becomes soluble at greater $\mathrm{pH}$; c) fulvic acid is the fraction of humic substances that is soluble under all $\mathrm{pH}$ conditions [1]. Humic substances form most of the organic component of soil, peat and natural waters, they influence the process of formation of fossil fuels, and they play a major role in the global carbon geochemical cycle. 
Interaction of humic substances with xenobiotics may modify the uptake and toxicity of these compounds, and affect the fate of pollutants in the environment [2]. Structure of humic substances is characterised by presence of numerous aromatic, carboxylic and phenolic functionalities, linked together with alkylmoieties, imparting a measure of flexibility to the polymer chains. The molecular weight range commonly quoted for fulvic acids is 500 to 5000 daltons (DA), while it is $>5000 \mathrm{Da}$ for humic acids and can extend to values $>1000000 \mathrm{Da}$ [1]. Aqueous solutions of humic substances are generally polydisperse, with size ranges differing according to the origin - aqueous, terrestrial, or marine - of the material in question.

Surface tension measurement defined humic substances as surface active substances [3]. The amphipilic nature of humic substances has given rise to the micellar model for these compounds [4]. Other studies have indicated that the spontaneous aggregation of aquatic solutions of humic substances can be intramolecular (involving single polymer molecule) or intermolecular (involving multiple chains) [5 - 7] and the interior of these assemblies is relatively hydrophobic, while the exterior is more hydrophilic. It has been suggested the way of arrangement of humic substances in solutions to describe as pseudomicellar [5].

Unless micellar structural model of humic substances has been suggested, in the same time there are only a few studies about the factors that affect the surface activity of humic solutions. The objective of this study is to study changes in surface activity depending on the origin and properties of humic substances.

\section{MATERIALS AND METHODS}

Humic substances were isolated from soil, peat and water in Latvia, representing different environments. Humic acids were extracted and purified using procedures recommended by the International Substance Society [8]. The obtained humic substances were characterised as described earlier by their elemental, functional and spectroscopic characteristics [9 - 13]. Industrially produced humic substances (Humid Acid Aldrich, USA, Lignohumate, RET, Russia) and synthetic humic material were used for comparison [16].

Surface tension measurements were taken with tensiometer Krüss K6, fitted with a $19 \mathrm{~mm}$ diameter platinum ring. Samples were prepared for measurement diluting till the appropriate concentration standard solution at humic substances $(1000 \mathrm{mg} / \mathrm{L})$ and equilibrating for 24 hours. Solutions were placed in a shallow glass dish of $50 \mathrm{~mm}$ diameter and the platinum ring was inserted in the middle of the container to avoid edge effects and equilibrated for 90 min. The ring was raised through manual operation of the torsion mechanism and the tension readings at the instant of surface detachment were noted. Kinetic measurements were performed after adding the appropriate amount of metal ions stock solution to $10 \mathrm{ml}$ of humic solution, stirring for $1 \mathrm{~min}$ and then taking data at appropriate intervals. All measurements were taken in triplicate at a temperature of $22 \mathrm{C}$ and mean results are used in the figures with standard deviation not more than $\pm 2 \mathrm{mN} / \mathrm{m}$.

The surface excess values, $\Gamma\left(\mathrm{mol} / \mathrm{cm}^{2}\right)$, (which represents the amount of HA molecules at an air-water interface), were calculated from the slope of $(\mathrm{d} \gamma / \mathrm{d} \ln C)$ in a concentration dependence of surface tension, Gibb's adsorption equation described it as follows:

$\Gamma=-\frac{1}{R T} \times \frac{d \gamma}{d \ln C}$ 
where: $\mathrm{R}$ is the gas constant, $\mathrm{T}$ is absolute temperature, $\gamma$ is the surface tension of the HA solution, and $\mathrm{C}$ is the concentration of humic substances [14].

Slope at the surface tension changes - $\Delta \gamma / \Delta \mathrm{C}$ is the change in surface tension $(\mathrm{mN} / \mathrm{m})$ per unit change in dissolved organic carbon concentration $(\mathrm{mg} \mathrm{C} / \mathrm{L})$ [15] for interval at concentration $150-250 \mathrm{mg} / \mathrm{L}$.

\section{RESULTS AND DISCUSSION}

The effect of humic substances on surface tension depends on their amphiphlic character and tendency to accumulate at the water-air interface. It is known that the behaviour of humic substances in aquatic solutions depends on their concentration, $\mathrm{pH}$, metal ion concentrations [5 - 7] and the same factors determines the influence of humic substances on the surface tension and the formation of pseudomicelles, since both are manifestations of the same solution properties. In the same time it is well known the dependence of properties of humic substances on their origin [1]. To study the changes of ability of humic substances to influence surface tension depending on their origin, we have used well characterised humic substances, isolated from soils, peat and aquatic sources [9-13] as well as industrially produced and synthetic humic matter.

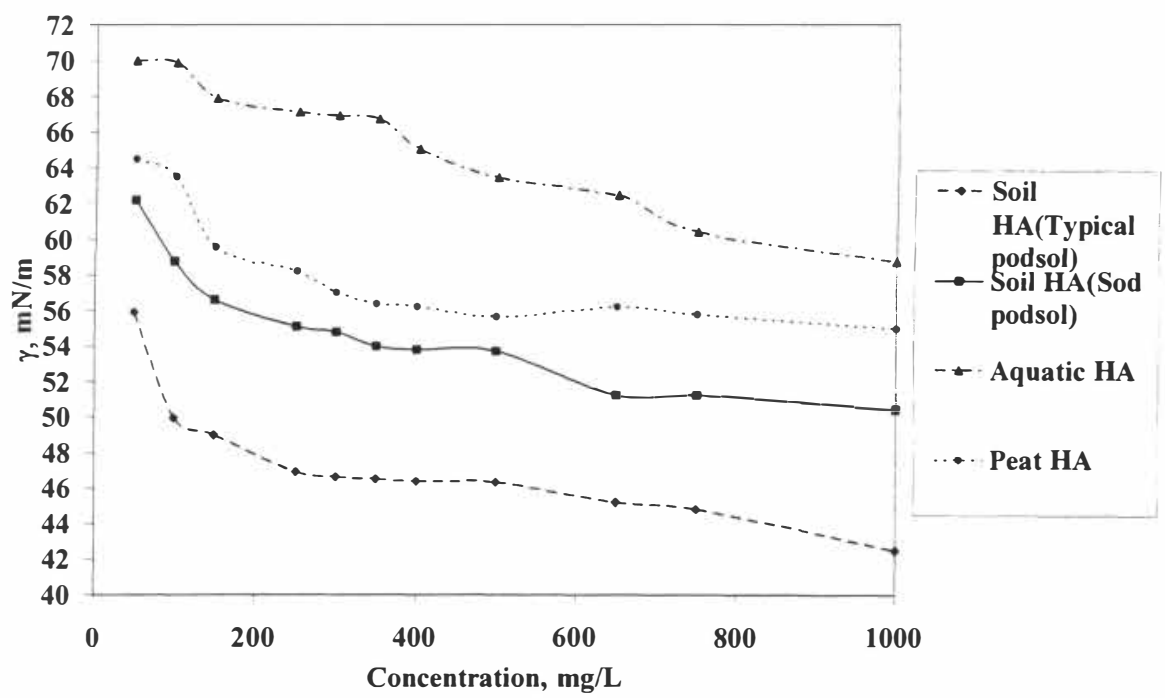

Figure 1. Variation of surface tension for humic acid solutions depending on their concentrations.

All studied humic substances demonstrate ability to influence surface tension of their solutions (Figure 1, 2). In concentration intervals from $50 \mathrm{mg} / \mathrm{L}$ to $1000 \mathrm{mg} / \mathrm{L} \gamma$ dropped from $56-70 \mathrm{mN} / \mathrm{m}$ to $43-59 \mathrm{mN} / \mathrm{m}$. The relative ability to influence surface tension can be characterized with slope at the concentration surface tension graph and it is higher for $\mathrm{HA}$ 


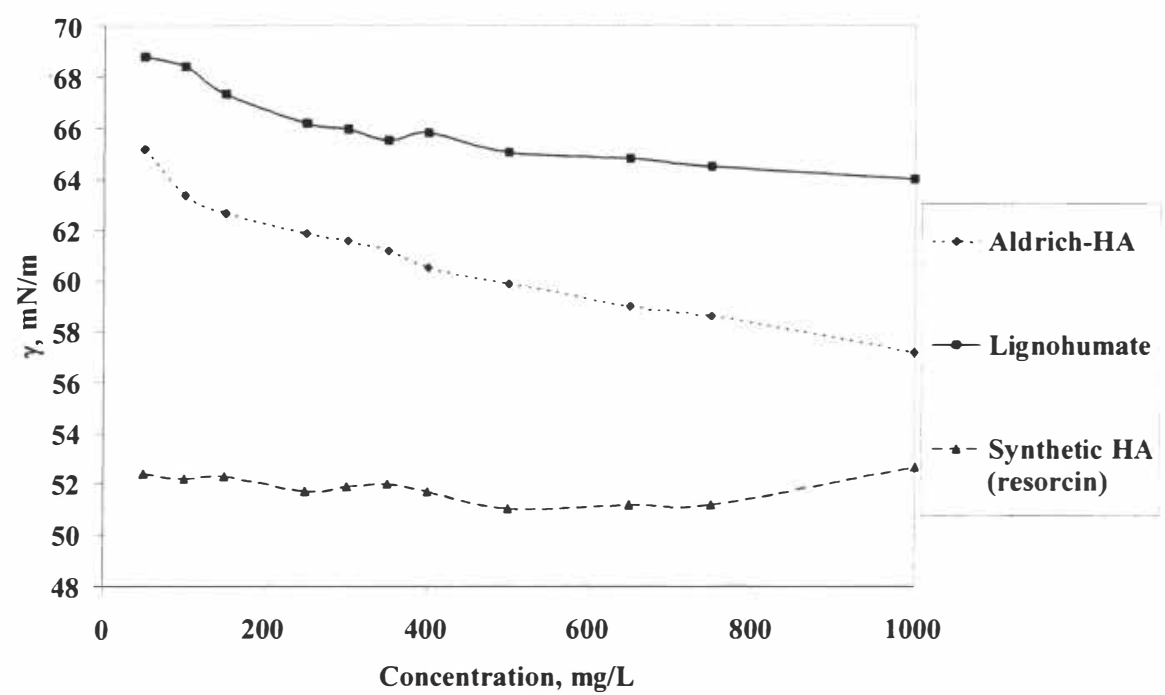

Figure 2. Variation of surface tension for industrially produced and synthetic humic acid solutions depending on their concentrations.

from soil (Table 1), but lowest for industrially produced and synthetic HA (Figure 2, Table 1). Probably, the reason for so significant differences can be the origin of industrially produced humic substances (usually they are extracted from low-rank coal).

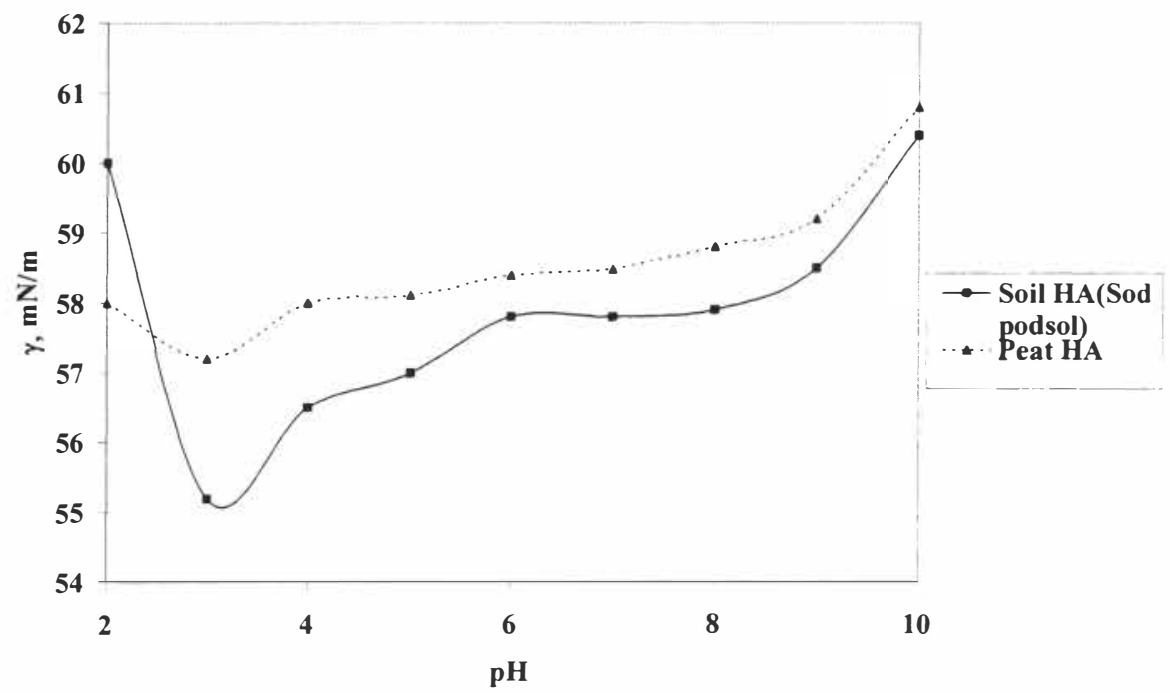

Figure 3. Variation of surface tension with $\mathrm{pH}$ for $100 \mathrm{mg} / \mathrm{L}$ humic acid solutions. 
The surface tension-pH curves featured a minimum for all solutions, declining steeply from higher and lower $\mathrm{pH}$ values. The measured surface tension was greatest at high $\mathrm{pH}(>8)$ in all cases, since the humic solute was highly anionic (and therefore very hydrophilic) under those conditions. The decrease in surface tension with decreasing $\mathrm{pH}$ reflects the gradual neutralization of acidic sites, which created amphiphilic species that migrated to the surface. The degree to which this occurred differed for different humic substances, being last pronounced for the fulvic acid. This may be attributed to the high functional group density on these relatively small molecules, which allowed fairly extensive $\mathrm{H}$ bonding with the aqueous solvent throughout the $\mathrm{pH}$ range and hindered the development of a strong amphiphilic character. In all cases the surface tension increased again in the low $\mathrm{pH}$ ranges where continued neutralization produced increasingly hydrophobic molecules with low surface activity.

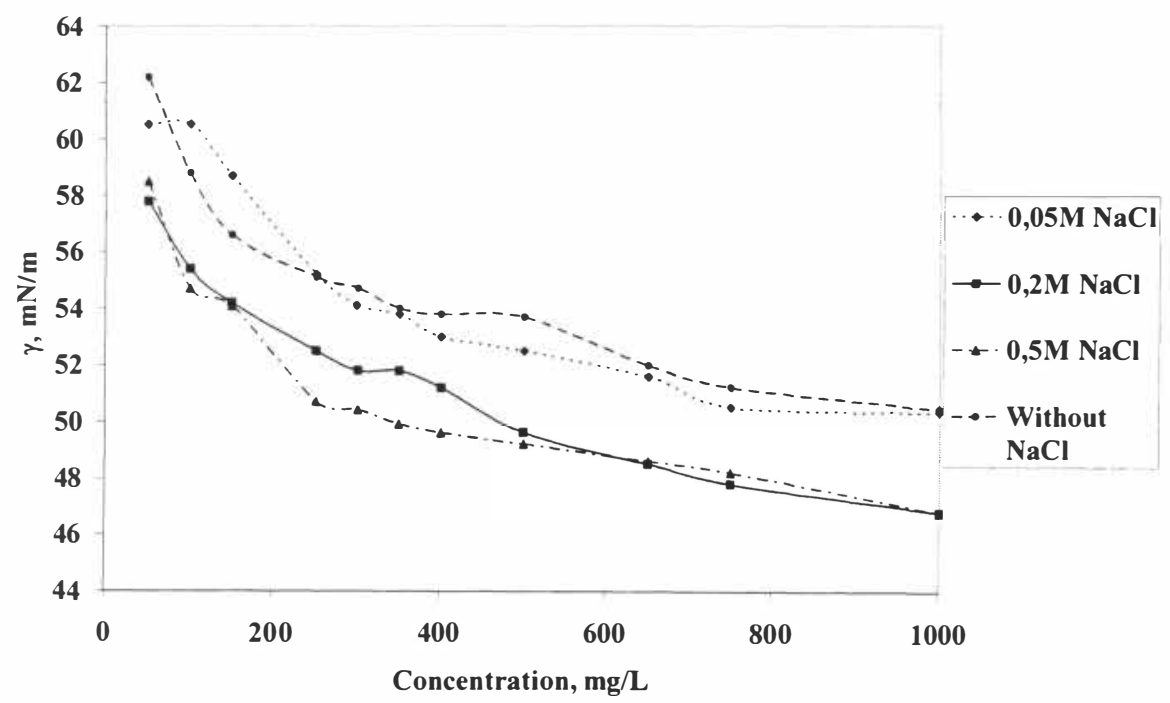

Figure 4. Variation of surface tension with sodium chloride concentration for soil humic acid solution. 


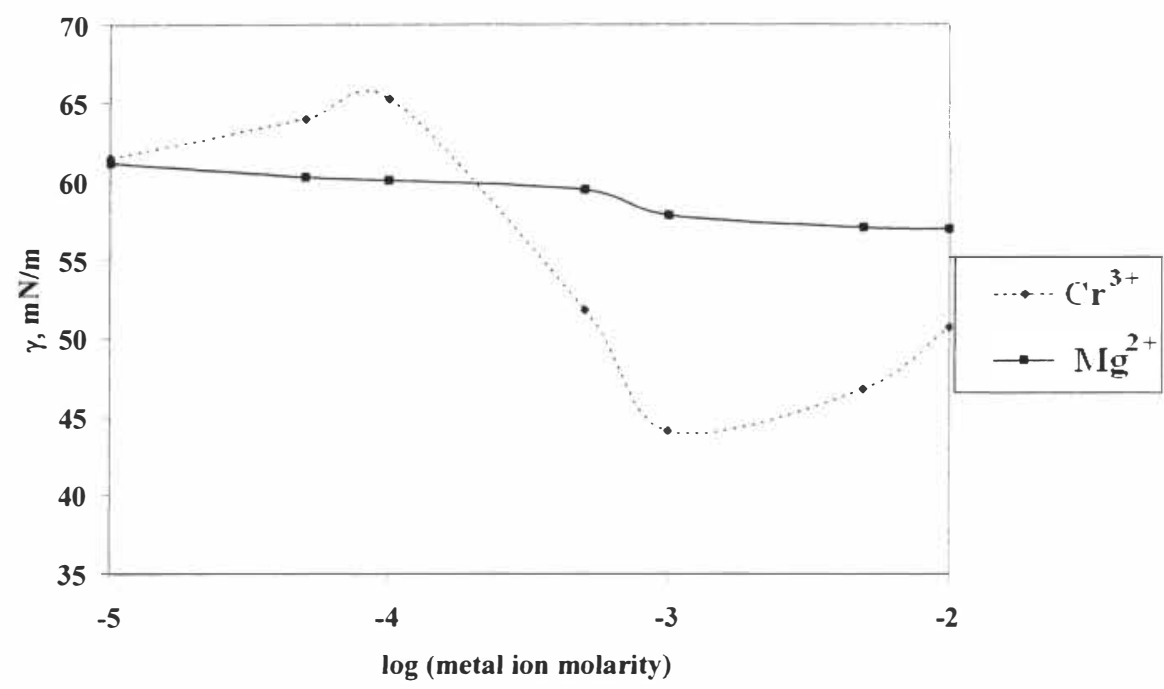

Figure 5. Variation of surface tension of $100 \mathrm{mg} / \mathrm{L}$ soil humic acid solution (pH 6) on metal ion concentration.

Presence at inorganic ions reduced the surface tension at humic solution indicating a salting out effect, but also formation of complexes with significantly differing ability to influence surface tension of aquatic solutions. So significant differences in the surface tension of humic solutions depending on the ion type, significant differences have been observed (Figures 4 , 5).

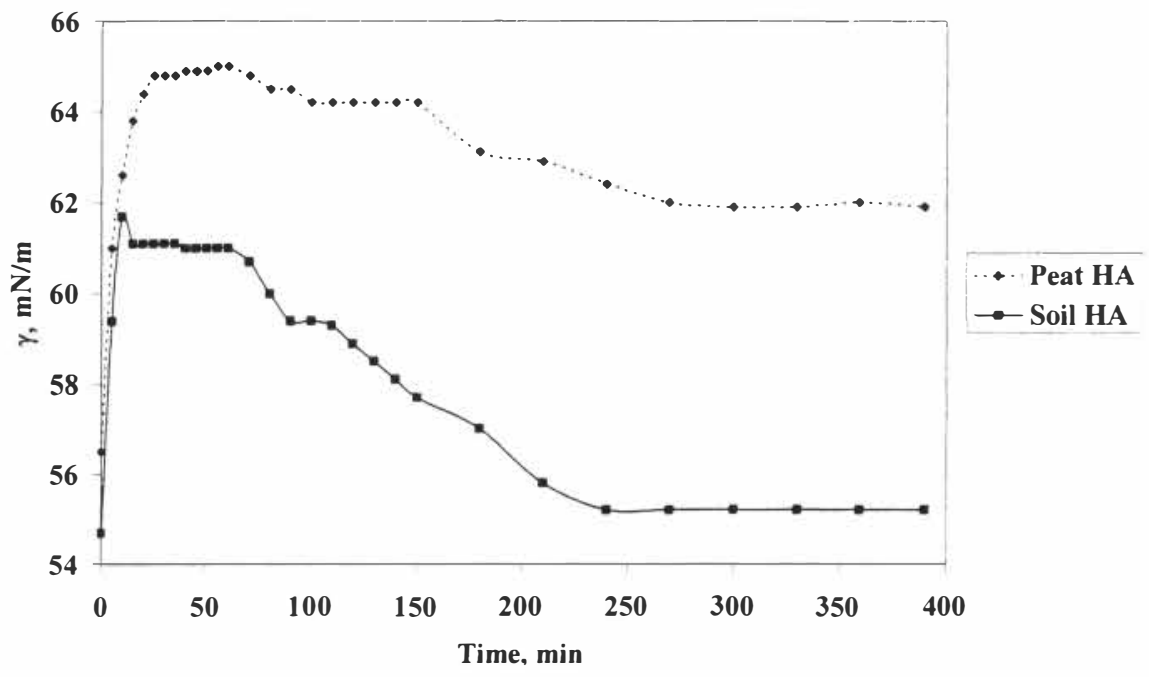

Figure 6. Variation of surface tension with time for $250 \mathrm{mg} / \mathrm{L}$ humic acid solutions. 
If in the presence of sodium and magnesium ions the surface tensions decreased with increasing metal ion concentration, then for chromium (III) ion the curve indicate ability to interact with humic substances forming complexes with increased surface activity.

Table 1. Slope at the surface tension changes $150-250 \mathrm{mg} / \mathrm{l}$ and the surface excess values.

\begin{tabular}{lcc}
\hline Humic substance & Slope, $(\mathrm{mN} / \mathrm{m}) /(\mathrm{C} / \mathrm{L})$ & Surface excess values, $\mathrm{mol} / \mathrm{cm}^{2}$ \\
\hline Tehum HA & -0.039 & $-1,0863 \cdot 10^{-4}$ \\
\hline Aldrich HA & -0.012 & $-7,4220 \cdot 10^{-5}$ \\
\hline Mexicano FA & -0.011 & $-4,0100 \cdot 10^{-6}$ \\
\hline Lignohumate HA & -0.013 & $-4.5296 \cdot 10^{-5}$ \\
\hline Synthetic HA with tannin & -0.015 & $-5.3246 \cdot 10^{-5}$ \\
\hline Synthetic HA (resorcin) & -0.012 & $-4.1013 \cdot 10^{-6}$ \\
\hline Soil HA (Typical podsol) & -0.021 & $-1,2095 \cdot 10^{-4}$ \\
\hline Soil HA (Humus gley) & -0.028 & $-1,6075 \cdot 10^{-4}$ \\
\hline Soil HA (Sod podsol) & -0.015 & $-1,0399 \cdot 10^{-4}$ \\
\hline Aquatic HA (Daugava) & -0.001 & $-1,0256 \cdot 10^{-4}$ \\
\hline Peat HA (Olaine) & -0.012 & $-5,4370 \cdot \overline{10^{-5}}$ \\
\hline Peat HA (Spigu) & -0.059 & $-4,5084 \cdot 10^{-5}$ \\
\hline Peat HA (Livanu) & -0.016 & $-9,0744 \cdot 10^{-5}$ \\
\hline Peat HA (Kemeru) & -0.005 & $-8,2688 \cdot 10^{-5}$ \\
\hline
\end{tabular}

Also the kinetics of the development of surface tension (Figure 6) shows significant changes of the surface tension, in the same time similar for all studied humic substances. The kinetics of the changes in surface tension illustrates the importance of the rearrangement of humic molecules in the solutions and impact of these processes on the surface tension.

\section{CONCLUSIONS}

The surface tension-pH curves of humic substances featured a minimum for all solutions, declining steeply from higher and lower $\mathrm{pH}$ values. The decrease in surface tension with decreasing $\mathrm{pH}$ reflects the gradual neutralization of acidic sites, which created amphiphilic species that migrated to the surface. Surface tension of solutions of humic substances decreased with increasing concentration, as well as in presence of metal salts. Many industrially produced humic materials demonstrated no or insignificant impact on surface tension of their solutions, but humic substances isolated from natural environments (water, soil, peat, sediments) demonstrated significant impact of surface tension of their solutions. Thus there exist direct links between origin, structure of humic substances and their ability to influence surface tension of aquatic solutions.

\section{REFERENCES}

[1] Kłavinšs M., 1998. Aquatic humic substances. Latvian University, Rīga, 234.

[2] Simpson M.J., Simpson A.J., Hatcher P.G., 2004. Noncovalent interactions between aromatic compounds and dissolved humic acid examined by nuclear magnetic resonance spectroscopy. Environ. Sci. Technol. 23(2), 355-362.

[3] Guetzloff T.F., Rice J.A., 1994. Does humic acid form a micelle? Sci. Total Environ., $152,31-35$. 
[4] Wershaw R.L., 1993. Model for humus in soils and sediments. Environ. Sci. Technol. $27, \mathrm{t} 814 \mathrm{t}-816$.

[5] Engebretson R.R., von Wandruszka R., 1994. Microorganization in dissolved humic acids. Environ. Sci. Technol. 28, $1934-1941$.

[6] Engebretson R.R., von Wandruszka R., 1996. Quantitative approach to humic acid associations. Environ. Sci. Technol. 30, $990-997$.

[7] Yates L.M., von Wandruszka R., 1999. Effects of $\mathrm{pH}$ and metals on the surface tension of aqueous humic materials. Soil Sci. Soc. Am. J. 63, $1645-1649$.

[8] Thurman, E. M., Malcolm, R. L., 1981. Preparative isolation of aquatic humic substances. Environ. Sci. Technol. 15, 463-466.

[9] Rozenbaha I., Odham G., Jarnberg U., Alsberg T., Klavins M., 2002. Characterisation of humic substances by acid catalysed transesterification. Anal.Chim.Acta 452, 105-114.

[10] Klavins M., Eglite L., 2002. Immobilisation of humic substances. Colloids and Surfaces A: Physicochem., Eng. Aspects 203, 47 - 54.

[11] Juhna T., Klavins M., Eglite L., 2003. Sorption of thumic substances on aquifer material at artificial recharge of groundwater. Chemosphere 51(9), 861-868.

[12] Eglīte L., Rozenbaha I., Odham G., Jarnberg U., Klavin̄š M., 2003. Reductive degradation of humic substances. Latv. Kìm.Ž. (3), 283-291.

[13] Klavin̄š M., Jankovska L., Būmane I, Kreišmanis J., 2004. Degradation of humic substances by UV irradiation, Latv. Kīm.ť. (4), 379-385.

[14] Kawahigashi M., Fujitake N., Tsurudome T., Suzuki S., Otsuka H., 1997. Changes in configurations and surface active properties of humic acid with increasing concentration of $\mathrm{NaCl}$. In: Proceedings of the $8^{\text {th }}$ IHSS meeting. The role of humic substances in the ecosystems and in environmental protection, Wroclaw, Poland, pp. $127-133$.

[15] Anderson, M.A., Hung A., Mills D., Scott M.S., 1995. Factors affecting the surface tension of soil solutions and solutions of humic acids. Soil Sci. 160, $111-116$.

[16] Klöcking, R., Mücke, D., 1969. Isolierung Waserlöslicher Huminsäuren (Fulvosäuren) aus ihren Blei(II) chelatverbindungen. Z. Chem. 12, 453-454. 